\title{
AGE DETERMINATION OF A SEDIMENT SAMPLE BY OPTICALLY STIMULATED LUMINESCENCE
}

\author{
Ivana Sandeva, Vladimir Dimčev, Margarita Ginovska, Lihnida Stojanovska-Georgievska, \\ Aleksandar Krleski, Hristina Spasevska
}

\author{
Faculty of Electrical Engineering and Information Technologies, \\ "Ss. Cyril and Methodius" University in Skopje, \\ P.O. box 574, 1001 Skopje, N. Macedonia \\ ivana@feit.ukim.edu.mk
}

\begin{abstract}
A b s t r a c t : Luminescence dating is an important method for age determination that is based on studying the luminescence characteristics of quartz and feldspar as the most common minerals in sediments and artifacts. The greatest advantage of this dating method is its wide dynamic range, starting from 10 years to 500000 years and its ability to be applied on many different materials and to a range of grain sizes, from fine slit to medium sand. Measurements in this paper are done on sediment samples by optically stimulated luminescence technique, including sample preparation and analysis of results.
\end{abstract}

Key words: optically stimulated luminescence; dating; minerals; sediments

\section{ОПРЕДЕЛУВАЫЕ НА СТАРОСТА НА ПРИМЕРОК ОД СЕДИМЕНТ СО ОПТИЧКИ СТИМУЛИРАНА ЛУМИНИСЦЕНЦИЈА}

\begin{abstract}
А п с т р а к т: Луминисцентното датирање претставува важен метод за определување старост заснован на луминисцентно испитување на кварц и фелдспат како најчести минерали во седиментите и артефактите. Најголемата предност на овој метод пред другите методи за датирање е во тоа што има широк динамички интервал, почнувајќи од десетина години, па сѐ до над 500000 години, како и можноста да се примени на многу различни материјали со различна големина на гранулите. Мерењата за овој труд се направени на примероци од седимент со помош на оптички стимулирана луминисценција и ја вклучуваат целата потребна подготовка на примероците и понатамошна анализа и обработка на резултатите.
\end{abstract}

Клучни зборови: оптички стимулирана луминисценција; датирање; минерали; седименти

\section{INTRODUCTION}

The basis of luminescence dating lies in the structure and properties of minerals. Minerals gain energy from internal and external radionuclides of the ${ }^{238} \mathrm{U},{ }^{232} \mathrm{Th}$ and ${ }^{40} \mathrm{~K}$ series, as well as from cosmic rays, by which some electrons jump to higher energy states [1]. In the process of return to their ground state, they may be trapped in some imperfections of the crystal lattice. Electrons stay in this state until they are exposed to optical or thermal stimulation, which gives them enough energy to leave the traps and recombine with holes. As a result of this recombination, photons are released and registered, i.e. a luminescence signal is detected.
The first assumption of luminescence dating is that the target material was completely emptied of trapped charge by its last exposure to light or heat. By this, the luminescence signal is reset, after which the sample starts over to accumulate energy.

Grains of the material play the role of natural dosimeters. The total absorbed dose is calculated by optically stimulated luminescence (OSL) or by thermoluminescence (TL). A comparison is made between the natural luminescence signal and luminescence signals after exposure of the sample to different laboratory doses, i.e. a calibration curve is obtained. 
The dose rate is calculated by gamma spectrometry. The second assumption of luminescence dating is that the dose rate has been constant through time.

Performance tests, including recycling, recuperation, thermal transfer, preheat plateau and dose recovery, as well as detailed studies show that this method for dating is precise and accurate.

Dose rate varies between 1 to $2 \mathrm{~Gy} \cdot \mathrm{ka}^{-1}$, where $1 \mathrm{~Gy}=1 \mathrm{~J} / \mathrm{kg}$, and $\mathrm{ka}$ represents a period of 1000 years. By measuring the total absorbed dose, the age of the analyzed sample can be determined.

\section{THEORETICAL BACKGROUND}

Electrons of a single atom are only allowed to exist in certain discrete energy levels. Energy values between these discrete levels are forbidden for an electron in a free atom. When atoms form a solid, individual energy levels of an atom break up and form bands of allowed energy states. These energy bands in the solid are separated by forbidden energy bands.

In a typical material, the two outermost bands are called the valence band and the conduction band, separated by a forbidden energy gap - the band gap. The valence band is the lower band of allowed states. Since electrons tend to fill the lowest available energy states, the valence band is almost always completely filled with electrons. The conduction band is the upper band of allowed states.

When imperfections are present in the crystal structure, electrons can jump between valence and conduction band, leaving free electrons in the conduction band and free holes in the valence band. This means that the imperfections in the crystal structure form new localized energy levels in the band gap. When minerals are exposed to ionizing radiation, electrons may gain enough energy to leave the energy band and be trapped in some imperfection of the lattice. When this material is later exposed to optical or thermal stimulation, trapped electrons gain energy to release and recombine with holes, thus emitting photons.

Thermoluminescence is the phenomenon of emission of light from irradiated solids when they are stimulated with heat. This is due to the absorbed radiation energy. When some material that is sensitive to TL is exposed to ionizing radiation, electron-hole pairs are formed, that can freely move through the conductance and valence band and some of them may be trapped in some active points in the material. Electrons remain in this state until they gain enough thermal energy to be released. When the material is heated, electrons gain energy, leave the current energy state and recombine with holes [2]. This process is followed by emission of light.

The process of optically stimulated luminescence is observed when electrons recombine with holes when the material is stimulated with light with wavelengths of $455-625 \mathrm{~nm}$. During the optical stimulation, the luminescence signal decreases because of reduction of number of trapped electrons.

Luminescence signal is detected by photon counting method, i.e. by the use of a photomultiplier tube.

\section{LUMINESCENCE DATING}

Luminescence as a dating method is developed by Martin Aitken in 1960 [3]. Quartz and feldspar grains play the role of natural dosimeters, giving information of the absorbed dose. The absorbed dose gives information of the last moment that the sample has been exposed to heat. Later, OSL was used as a complementary method for dating.

OSL and TL may be used for dating of sediments and archaeological artifacts. In order to do that, one has to determine the total dose of ionizing radiation that the sample has absorbed since its last exposure to heat or light, and that is the moment that it is assumed the sample was completely emptied, i.e. no electrons were left trapped in the lattice; and to determine the concentration of radionuclides, thus determining the dose rate [4]. The age of the sample can then be calculated by the following simple formula:

$$
\begin{gathered}
\text { Age }=\text { Dose/Dose rate } \\
\alpha+\beta=\chi .
\end{gathered}
$$

The process of age determination by luminescence methods is schematically shown in Figure 1.

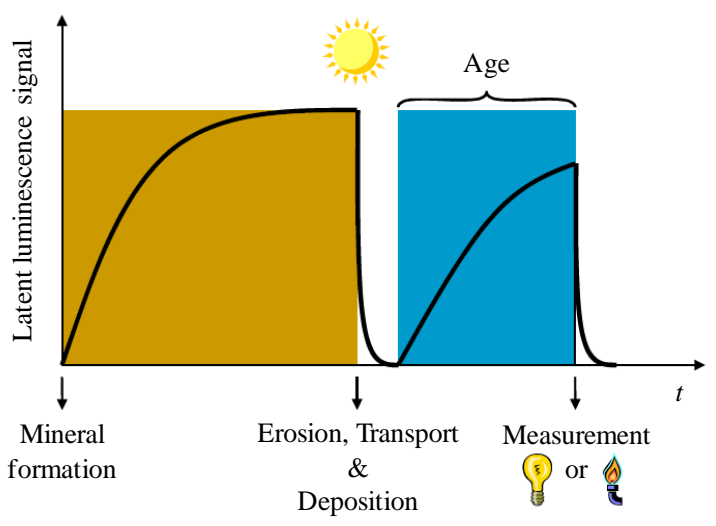

Fig. 1. Luminescence signal intensity $I$ versus time $t$ [5] 
After an appropriate chemical preparation, the sample is measured using TL or OSL reader. The absorbed dose is determined by comparison of the natural luminescence and the signal obtained after a known laboratory dose. This can be done by exposing the sample to different doses and obtaining a calibration curve. The dose rate is determined by gamma spectrometry.

In order to apply this method for dating, two general assumptions have to be made. The first assumption states that the sample was completely emptied during its last exposure to heat or light; and the other one states that the dose rate has been constant through time. Considering the first assumption, OSL is a more reliable method than TL [6].

\section{APPLICATION OF LUMINESCENCE DATING}

\section{Apparatus}

A schematic diagram of an OSL instrument is shown in Figure 2.

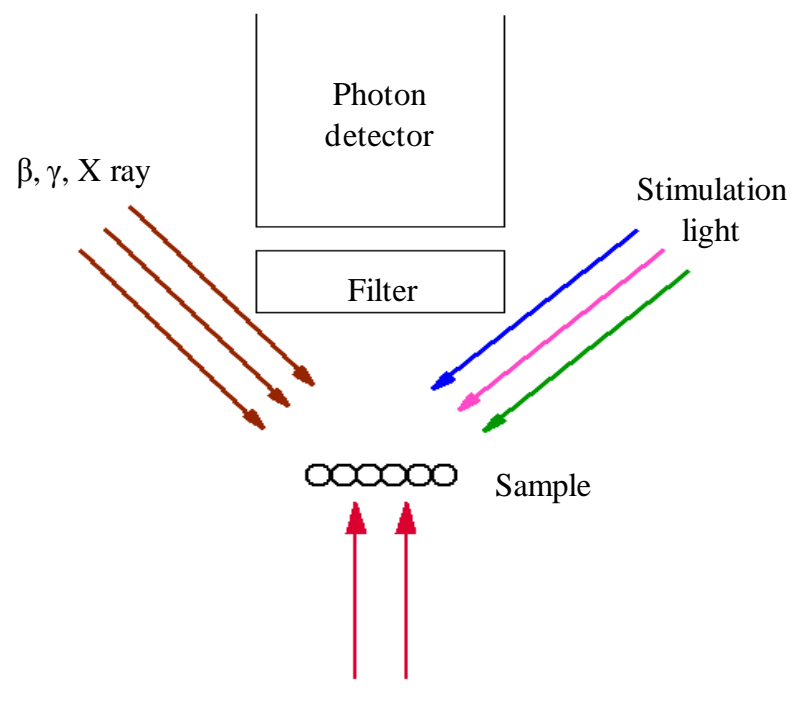

Heat

Fig. 2. Schematic diagram of an OSL instrument

The apparatus for detection of TL and OSL used for our measurements comprises a sample carrousel and a sensitive photon counter or a photomultiplier for measurement and amplification of emitted light. The sample is placed on a heater plate and is heated by a thermocouple. Emitted light is focused to the photomultiplier through a filter. The main parts of the used TL/OSL reader are schematically shown in Figure 3.

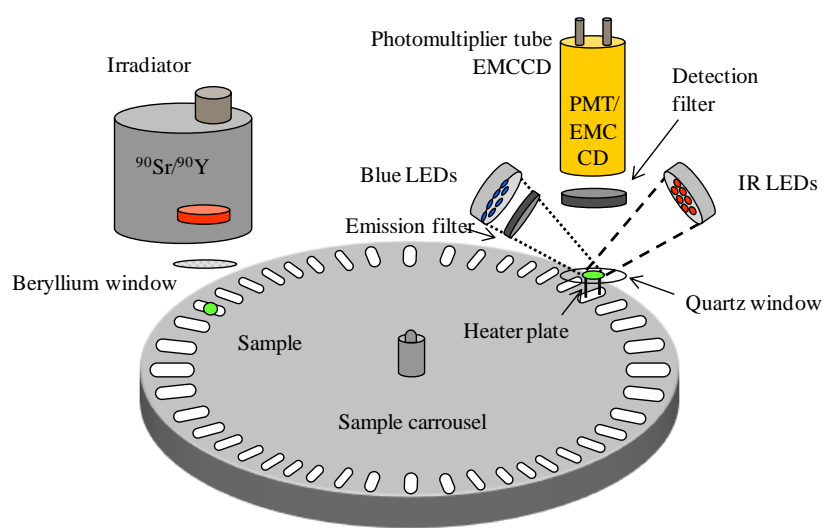

Fig. 3. Main parts of the TL/OSL reader [7]

The Riso TL/OSL reader Model DA-20 used for measurements is shown in Figure 4.

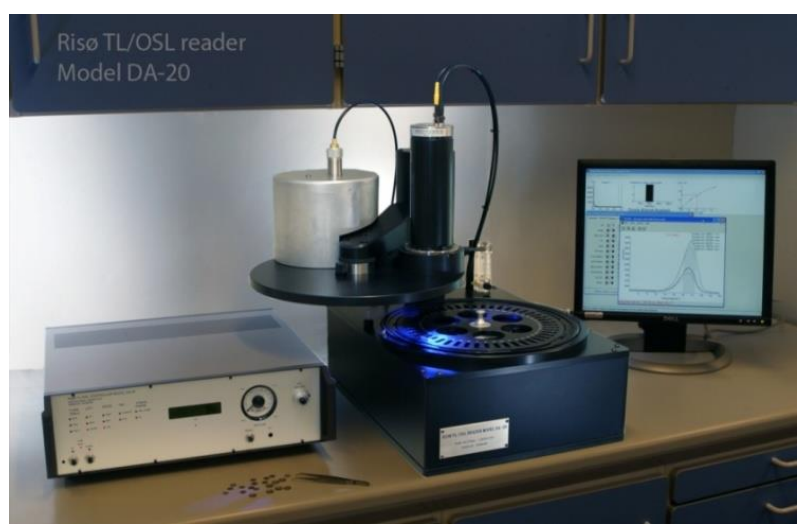

Fig. 4. TL/OSL reader [8]

Depending on the type of material, the sample may be stimulated with light with different wavelengths, which is enabled by the use of filters. Blue, green and infrared filters are the most common filters. The intensity of stimulating light is approximately $10^{18}$ times higher than the intensity of the light emitted from the sample.

As a source for radiation, either $\mathrm{X}$-ray source, alpha source $\left({ }^{241} \mathrm{Am}\right)$ or beta source $\left({ }^{90} \mathrm{Sr} /{ }^{90} \mathrm{Y}\right)$ can be used. For our measurements, a ${ }^{90} \mathrm{Sr}$ beta source is used, characterized by activity of $1.48 \mathrm{GBq}(\sim 0.1$ $\mathrm{Gy} / \mathrm{s}$ ), maximum energy of $2.27 \mathrm{MeV}$ and a half-life of approximately 30 years. The beta dose actually comes from the decay of strontium, that is yttrium, which has a half-life of 64 hours. The radioactive source in the reader is shielded in a lead container.

\section{Single aliquot regenerative-dose (SAR) method}

Intensity of luminescence signal from the sample depends on the absorbed dose. Taking this into 
account, by comparing the natural signal and the signal after a known laboratory dose, the absorbed dose can be calculated (Figures 5 and 6).

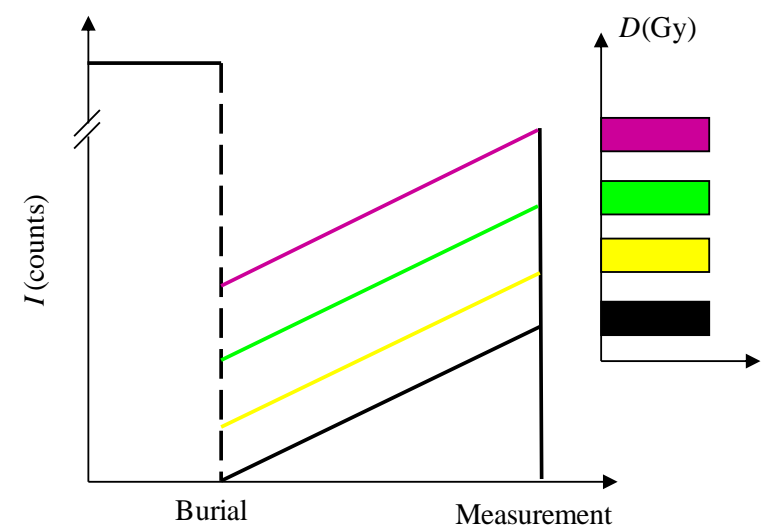

Fig. 5. The OSL signal is dependent on the absorbed dose

For the measurement procedure, the sample is exposed to a certain dose $D_{\mathrm{i}}$, then it is heated and it is optically stimulated, OSL intensity $L_{\mathrm{i}}$ is measured, a test dose $D_{\mathrm{t}}$ is given, the sample is heated again and it is optically stimulated and the OSL intensity $T_{\mathrm{i}}$ is measured [9-10]. At the end, a comparison of OSL intensities is done. By this, the laboratory dose that gives the same signal as the natural dose can be determined.

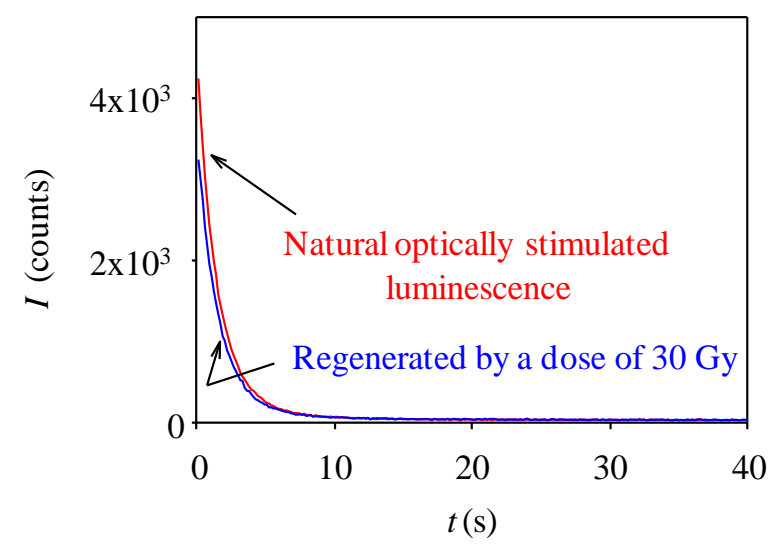

Fig. 6, Intensity of luminescence $I$ as a function of time $t$

In order to check the performance of the procedure, some tests are done, including tests of recycling (can the measurement be repeated accurately), recuperation (does the growth curve pass through the origin), thermal transfer (does a fully bleached sample give zero dose), preheat plateau (is the dose estimate independent of thermal treatment) and dose recovery (can a known dose given before any thermal treatment be measured).
Measurement conditions are different than natural conditions. That is why it is important to preheat the sample in order to empty it from unstable traps and to prevent a completely empty sample from giving a luminescence signal because of thermal transfer [11], as well as to sensitize all signals to same degree. Depending on the type of sample, preheat is done under different temperatures and time length [12]. Thus, a clear OSL signal that is thermally stable is produced [13].

The apparatus is supported by appropriate software for processing of results, which comprises the programs Analyst, Control Program, Sequence editor and Viewer.

Gamma spectrometry is used for determination of dose rate, i.e. the rate of deposition of radiation energy in the sample. Gamma spectrometry actually determines the concentration of different radionuclides in the sample, which then needs to be converted into dose rate. By doing this, it is assumed that the range of radiation is less than the dimensions of the sample and that the rate of absorption of energy over unit mass of the sample is equal to the rate of emission of energy from unit mass of the sample [1]. This means that the sample has to be homogeneous in the range of at least 3-4 $\mathrm{mm}$ for beta radiation and $0.3 \mathrm{~m}$ for gamma radiation.

Water present in the sample is usually not radioactive, meaning that water content corrections have to be done.

There are certain limitations of this method for dating. Routine dosimetry of quartz and feldspar can determine doses of $\sim 1-200 \mathrm{~Gy}$, which correspond to age of hundreds to 150000 years. The system is able to register signals with the following characteristics:

$$
\begin{gathered}
S=I-b \succ 3 \sqrt{b} \\
\alpha+\beta=\chi
\end{gathered}
$$

where $S$ is the signal, $b$ is background and $I$ is the initial value of the signal.

For final determination of the absorbed dose, the following parameters are necessary: the absorbed dose calculated by the software $D_{\mathrm{e}}$, the dose rate, grain size, water content, geographic location of the sample site, and uncertainties of all these parameters.

Studies show that this procedure for retrospective dosimetry of quartz is very precise, with uncertainty of only around $1 \%$, and also the determination of equivalent dose is independent of the test dose in 
the interval of $8-120 \%$ of the natural dose. Moreover, the result is independent of previous heat treatment [14]. It has been shown that even heating of samples up to $1000{ }^{\circ} \mathrm{C}$ has no effect on precision of measurements [15].

\section{Sample preparation}

Measurements are done on sediment samples. Part of them is chemically prepared for OSL measurements. OSL results are obtained by a TL/OSL reader. Part of the samples is used for gamma spectrometry and the other part is used for saturation water content measurements.

Before the preparation, the outer part of the material needs to be removed, thus reducing the chance of measuring a bleached sample. For ceramics and rocks, first the outer part is to be removed, then the inner part crushed into pieces.

The inner part is thoroughly chemically prepared by wet sieving, treating with $\mathrm{HF}, \mathrm{HCl}$ and $\mathrm{H}_{2} \mathrm{O}_{2}$, washing with water and drying. By this, carbonates and organics are removed and only quartz and feldspar are left in the sample. When investigating quartz, it has to be separated from feldspar. In order to check if the sample has been cleaned from feldspar, one can stimulate the sample with infrared light. Samples containing feldspar give significant signal to this stimulation [16].

The outer part of the material that has been removed is used for water content measurements and for gamma spectrometry. Depending on the type of the gamma spectrometer the material is first crushed (if ceramics or rocks are to be measured), then grinded into small grains and then heated to high temperature in order to remove organic parts. After that it is mixed with hot wax to form a shape that is appropriate for the gamma spectrometer.

The inner part of the sample is prepared under subdued light, whereas the outer part that is used for water content measurements and for gamma spectrometry may be exposed to light as these measurement do not include OSL (Figure 7).

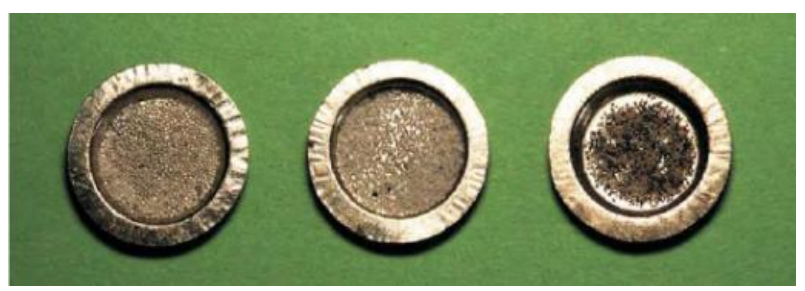

Fig. 7. Sediment samples prepared for measurement [18]
Prepared sample is put in steel cups suitable for the reader. Grains have to be spread in the cups in an even layer in order to prevent the different parts of the sample to absorb different doses. No two quartz grains are alike and also very few give a signal, making it reasonable to repeat the measurements with a few portions of the same sample [17].

\section{RESULTS}

Measurements are done on sediment samples from North-Western Denmark, taken from a point with altitude of $0 \mathrm{~km}$, laying $8^{\circ}$ North and $57^{\circ}$ East. The samples are taken from depth of $8 \mathrm{~m}$ and put in light tight containers to prevent bleaching. The samples are then prepared according to the described procedure for extraction of quartz. For measurements, grains with dimensions in the interval $180-250 \mu \mathrm{m}$ are chosen. Measurements for dose determination are done on Riso TL/OSL Reader model DA-20.

The beta source in the Riso TL/OSL Reader was calibrated by sensitised quartz grains with dimensions in the interval $180-250 \mu \mathrm{m}$, irradiated with a ${ }^{137} \mathrm{Cs}$ source with a dose of $4.81 \mathrm{~Gy}$ from the Nordic Center for Luminescence Research. Exposing the quartz samples to beta irradiation of the source for different periods of time, and then measuring the optically stimulated luminescence signal for each irradiation, a calibration curve was obtained, from which it was calculated that the dose rate of the source is $0.085 \mathrm{~Gy} / \mathrm{s}$. The performance of the procedure was checked according to the abovementioned tests of recycling, recuperation, thermal transfer, preheat plateau and dose recovery.

For the dose the value $3.99 \pm 0.12$ Gy was calculated by measuring the OSL response of several samples. Measurements for determination of dose rate are done by using gamma spectrometry and the value $0.95 \pm 0.1 \mathrm{~Gy} / \mathrm{ka}$ was obtained.

Taking into account all necessary factors (absorbed dose, dose rate, water concentration, and geographic location) for the age of the samples the value $4.21 \pm 0.14$ ka was obtained.

All uncertainty values are experimental and represent the standard deviations, whereas the uncertainty of the final age was calculated by combining uncertainties of all relevant factors, including systematic effects.

Previous studies [19] from the similar site found sediments dating back to $4200-4400$ years ago and these results are in a good agreement with ${ }^{14} \mathrm{C}$ dating results, making this the expected age. 


\section{CONCLUSION}

Luminescence dating has a wide dynamic range. This method is applicable to different kinds of samples and can be successfully applied to age determination of sediments, artifacts, rocks, etc.

Sampling, sample preparation and analysis of results are very time and resources consuming, but studies show that this method for dating is very precise. This dating method is being continuously improving, thus reducing problems regarding insensitive samples, incomplete removal of unstable defects, age outside the applicable range, etc.

The described dating method is applied to sediment samples. Samples have undergone complete chemical preparation, gamma spectrometry, measurements with TL/OSL reader and appropriate analysis of results.

By using the same basic techniques applied here, optically stimulated luminescence and thermoluminescence are also used for more fundamental studies regarding atomic structure of materials.

Acknowledgement: Authors would like to thank International Atomic Energy Agency for their donation and the Danish Technical University for their technical help and knowledge transfer.

\section{REFERENCES}

[1] Aitken, M. J.: Thermoluminescence Dating. Academic Press Inc. (London) LTD, 1985.

[2] Jensen, L. B.: Luminescence techniques: Instrumentation and methods, Radiation Measurements, Vol. 27, No. 5/6, pp. 749-768 (1997).

[3] Wintle, A. G.: Fifty years of luminescence dating, Archaeometry, Vol. 50, No. 2, pp. 276-312 (2008).

[4] Murray, A. S., Olley, J. M.: Precision and accuracy in the optically stimulated luminescence dating of sedimentary quartz: a status review, Geochronometria, Vol. 21, pp. 1-16 (2002).

[5] Vandenberghe, D.: Investigation of the optically stimulated luminescence dating method for application to young geological sediments, $\mathrm{PhD}$ thesis. University of Gent, Gent, Belgium, 2004.
[6] Rink, W. J.: Beyond ${ }^{14}$ C Dating: A User's Guide to Longrange Dating Methods in Archaeology. School of Geography and Geology, McMaster University, Ontario, Canada.

[7] DTU Nutech Center for Nuclear Technologies. Guide to The Risø TL/OSL Reader (2017). https://www.nutech.dtu.dk/english/products-and-services/ radiation-instruments/tl_osl_reader.).

[8] Furetta, C.: Handbook of Thermoluminescence. World scientific Publishing Co. Pte. Ltd. Singapore, 2010.

[9] Ratovonjanahary, A. J. F., Raboanary, R., Andriambololona, R., Goeksu, H. Y.: "Quartz glow-peaks lifetime analysis: TL glow-curve deconvolution functions for first order of kinetic compared to initial rise method", HEPMAD'04 Conference, Madagascar, 2004.

[10] Wintle, A. G., Murray, A. S.: Towards the development of a preheat procedure for OSL dating of quartz, Radiation Measurements, Vol. 29, No. 1, pp. 81-94 (1998).

[11] Wintle, A. G., Murray, A. S.: Quartz OSL: Effects of thermal treatment and their relevance to laboratory dating procedures, Radiation Measurements, Vol. 32, pp. 387-400, 2000

[12] Ankjaergaard, C., Murray, A. S., Denby, P. M.: Thermal pre-treatment in the OSL dating of quartz: Is it necessary? Radiation Protection Dosimetry, Vol. 119, No. 1-4, pp. 470-473 (2006)

[13] Banerjee, D., Jensen, L. B., Murray, A. S.: Retrospective dosimetry: Estimation of the dose to quartz using the singlealiquot regenerative-dose protocol, Applied Radiation and Isotopes, Vol. 52, pp. 831-844 (2000).

[14] Chen, G., Murray, A. S., Li, S-H.: Effect of heating on the quartz dose-response curve:, Radiation Measurements, Vol. 33, pp. 59-63, 2001.

[15] Duller, G.A.T., Jensen, L. B., Murray, A. S.: Combining infrared- and green-laser stimulation sources in single-grain luminescence measurements of feldspar and quartz, Radiation Measurements, Vol. 37, pp. 543-550 (2003).

[16] Murray, A. S., Roberts, R. G.: Measurement of the equivalent dose in quartz using a regenerative-dose single-aliquot protocol, Radiation Measurements, Vol. 29, No. 5, pp. 503515 (1998).

[17] Ankjaergaard, C.: Electron emission from natural minerals: implications for charge movement and dosimetry. $\mathrm{PhD}$ thesis, University of Copenhagen, Copenhagen, Denmark (2006).

[18] Murray, A. S., Clemmensen, L. B.: Luminescence dating of Holocene aeolian sand movement, Thy, Denmark, Quaternary Science Reviews, Vol. 20, pp. 751-754 (2001). 